\title{
Wind Tunnel Test for Videogrammetric Deformation Measurement of UAV for Mars Airplane Balloon Experiment-1 (MABE-1)*
}

\author{
Koji Fujita1 ${ }^{(1)}$, Akira Oyama², Daisuke Kubo³ ${ }^{3}$ Masahiro Kanazaki ${ }^{4}$, Hiroki Nagai ${ }^{1}$ \\ ${ }^{1}$ Institute of Fluid Science, Tohoku University, Sendai, Japan \\ ${ }^{2}$ Institute of Space and Astronautical Science, Japan Aerospace Exploration Agency, Sagamihara, Japan \\ ${ }_{3}^{3}$ Japan Aerospace Exploration Agency, Mitaka, Japan \\ ${ }^{4}$ Tokyo Metropolitan University, Hino, Japan \\ Email: fujita.koji@tohoku.ac.jp
}

How to cite this paper: Fujita, K., Oyama, A., Kubo, D., Kanazaki, M. and Nagai, $\mathrm{H}$. (2019) Wind Tunnel Test for Videogrammetric Deformation Measurement of UAV for Mars Airplane Balloon Experiment-1 (MABE-1. Journal of Flow Control, Measurement \& Visualization, 7, 87-100. https://doi.org/10.4236/jfcmv.2019.72007

Received: December 17, 2018

Accepted: March 6, 2019

Published: April 4, 2019

Copyright $\odot 2019$ by author(s) and Scientific Research Publishing Inc. This work is licensed under the Creative Commons Attribution International License (CC BY 4.0).

http://creativecommons.org/licenses/by/4.0/

\begin{abstract}
This paper reports the results of the aerodynamic deformation measurements of the meter-scale, entire shape, actual UAV in the wind tunnel using a video grammetry technique. The measured airplane was the airplane for Mars exploration being developed by Japan Aerospace Exploration Agency (JAXA) and Japanese universities. Its main wing span length was $2.4 \mathrm{~m}$. The video grammetry measurement was performed using VICON's system. Retroactive markers and stickers were put on the airplane. JAXA's $6.5 \mathrm{~m} \times 5.5 \mathrm{~m}$ Low-Speed Wind Tunnel was used. The airplane was mounted on the strut support with pitch-free or pitch-locked conditions. The deformations of the main wing bending, the main wing twisting, the tail boom bending, and the elevator deflection angle change were revealed quantitatively. The bending stiffness of a main wing spar that was designed as a safety factor of 2.8 at load factor of 5 was sufficient. The main wing spar was located around a center of pressure of an airfoil and it showed enough stiffness for twisting at nominal condition. The effects of the main wing bending and twisting, and the tail boom bending on the aerodynamic performance were estimated but they were in an acceptable range from the standpoint of the controllability of the aerodynamic performance using control surfaces. Even though the servo motor was located near the elevator and the linkage between the servo motor and the elevator was short, the measured elevator deflection angle was at most $4 \%$ smaller than the angle at no-wind condition. The obtained results and presented method are useful for control, flight data analysis, and design of lightweight airplanes.
\end{abstract}

${ }^{*}$ A part of this work was presented at 15 th International Conference Fluid Dynamics (ICFD15) inSendai, 7-9 Nov. 2018. 


\section{Keywords}

Wind Tunnel, UAV, Deformation, Video Grammetry, Mars Exploration

\section{Introduction}

Airplane for Mars exploration (Mars airplane) is a new Mars observation platform that enables wide-range observation from low altitude. Since 2010, the working group for Mars exploration aircraft has been working on a conceptual design and various fundamental researches of the Mars airplane [1] [2] [3] [4].

Flight tests are an important step of the airplane development to confirm the actual performance. However, the flight test of the Mars airplane has several difficulties. First difficulty is an unconventional flight environment. Atmospheric density on Mars is only about $1 \%$ of the density on Earth. In addition, average atmospheric temperature on Mars is about -40 degC. To simulate such flight environment, the Mars airplane has to conduct flight tests at high altitude atmosphere on Earth. The flight test altitude is around $35 \mathrm{~km}$. A special balloon is used to ascend the airplane to that altitude. Therefore the flight test is expensive and the chance of the test is limited. Second difficulty is the cost of the test airplane. The test airplane is expensive because the airplane is not a mass production and it has special payloads and avionics for academic research. Third difficulty is an aerodynamic deformation. To fly in such rare atmosphere, the Mars airplane has to be lightweight. Therefore the amount of the deformation of the Mars airplane may be relatively large. Due to such reasons, even though the flight test of the Mars airplane is important and possible, it is highly difficult and expensive.

In a conventional development process of Unmanned Aerial Vehicles (UAVs) and Micro Aerial Vehicles (MAVs), to conduct a flight test is relatively easy because it can be conducted at low altitude atmosphere on Earth and the cost of the airplane is not so high. Therefore the flight test is able to be conducted without detailed investigation of the uncertainties such as an aerodynamic deformation, with accepting some risk of a failure due to the uncertainties. However, the flight test of the Mars airplane is neither easy nor low cost. In such circumstance, it is important to reveal the amount of the aerodynamic deformation before the flight test to increase a success rate of the flight test.

In this research, the aerodynamic deformation of the airplane for a high-altitude flight test named "Mars Airplane Balloon Experiment-1 (MABE-1)" [5] [6] [7] was directly measured in a large wind tunnel using a video grammetry technique. Then, the effects of the deformation on the aerodynamic performance were estimated using the wing element theory to evaluate the impact on the entire aerodynamic performance.

There are many articles about aerodynamic deformation measurement for wing models and MAVs using a wind tunnel [8] [9]. However, the measurement 
of the meter-scale, entire shape, actual UAV is very few. Therefore the results obtained in this research are useful for not only the development of the Mars airplane but also the structural and aerodynamic designs of the light-structure airplanes that are expected large aerodynamic deformation. In addition, this research provides a valuable instance of the part of the development process of the airplane that is hard to conduct flight tests such as an expensive custom-ordered airplane for academic use, an airplane that cannot conduct many flight tests, an airplane for unconventional flight condition, an airplane that may deform largely, an airplane that has large uncertainty, and an unconventional airplane that has no flight experience.

\section{Experimental Setup}

This section describes a specification of a tested airplane, a wind tunnel, a video grammetry system, and experimental conditions.

\subsection{Airplane}

Table 1 and Figure 1 show the principal dimensions and the outline drawing of the airplane for MABE-1. Figure 2 shows a three-view drawing of the airplane. The fuselage was made by Carbon Fiber Reinforced Plastic (CFRP). Figure 3 shows main wing structure. The main wing structure consisted of a main spar, ribs, a trailing edge spar, and a skin. These members were also made by CFRP. The main spar was designed as a safety factor of 2.8 for bending at a load factor of 5 . The height, the width, and the thickness of the main spar were 27,20 , and 1 $\mathrm{mm}$, respectively. The thickness of the rib was $0.25 \mathrm{~mm}$. The skin covered the rib from the leading edge to main spar, i.e. the skin formed a D-box structure. The main spar was located on a center of pressure of the airfoil at nominal flight condition; therefore, the twisting moment was expected to be small when the center of pressure was around the main spar. The fuselage and the tail were connected by a tail boom, as shown in Figure 4. The tail boom was made by two CFRP pipes. One was a main boom and another was an additional reinforcing boom. The second pipe was added based on a static load test conducted beforehand. The diameter and thickness of the both pipes were $13 \mathrm{~mm}$ and $0.5 \mathrm{~mm}$. The tail structure consisted of a main spar, ribs, leading and trailing edges. These members were made by wood. The servo motor for the elevator actuation was DS189HV-ALM-KU (VACUUM) [10]. Its rated torque is $3.5 \mathrm{kgf} \cdot \mathrm{cm}$. The servo motor was located near the elevator to keep a length of a linkage short.

Table 1. Principal dimensions of airplane for MABE-1.

\begin{tabular}{ccc}
\hline Items & Values & Units \\
\hline Airplane length (w/o Air Data Sensor) & 2.0 & $\mathrm{~m}$ \\
Wing span & 2.4 & $\mathrm{~m}$ \\
Chord length & 0.5 & $\mathrm{~m}$ \\
Height (w/o attitude sensor) & 0.4 & $\mathrm{~m}$ \\
Dihedral angle of outer wing & 5 & $\mathrm{deg}$ \\
\hline
\end{tabular}




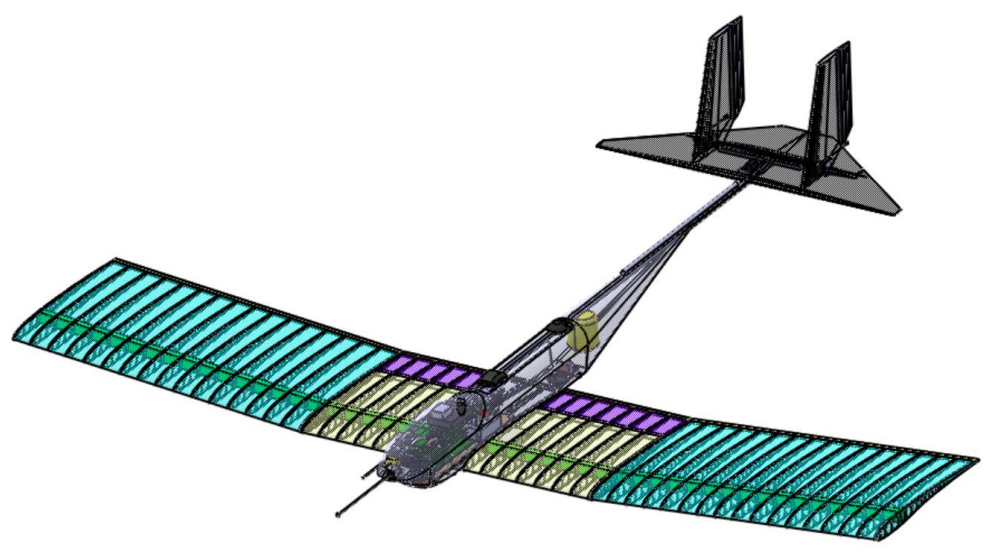

Figure 1. Outline drawing of airplane for MABE-1.
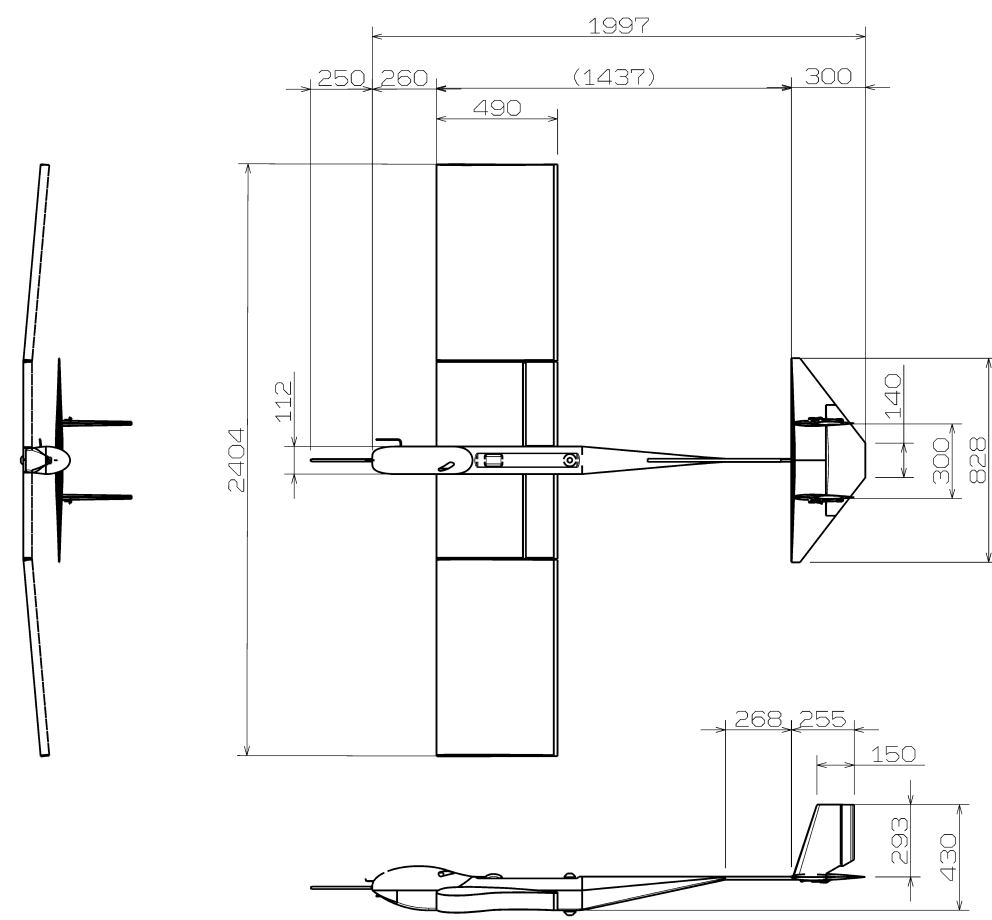

Figure 2. Three-view drawing.

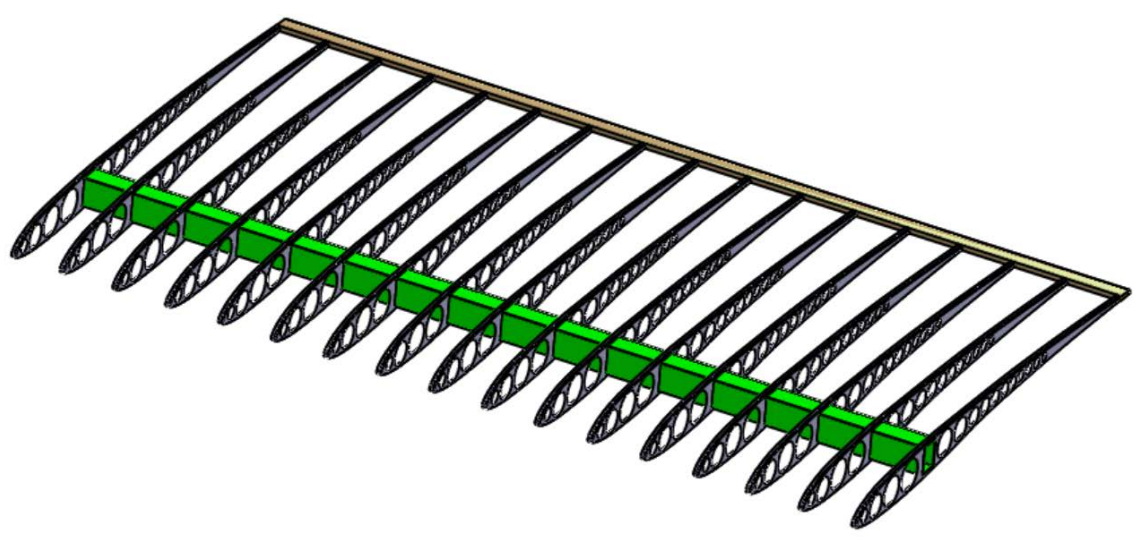

Figure 3. Main wing structure. 


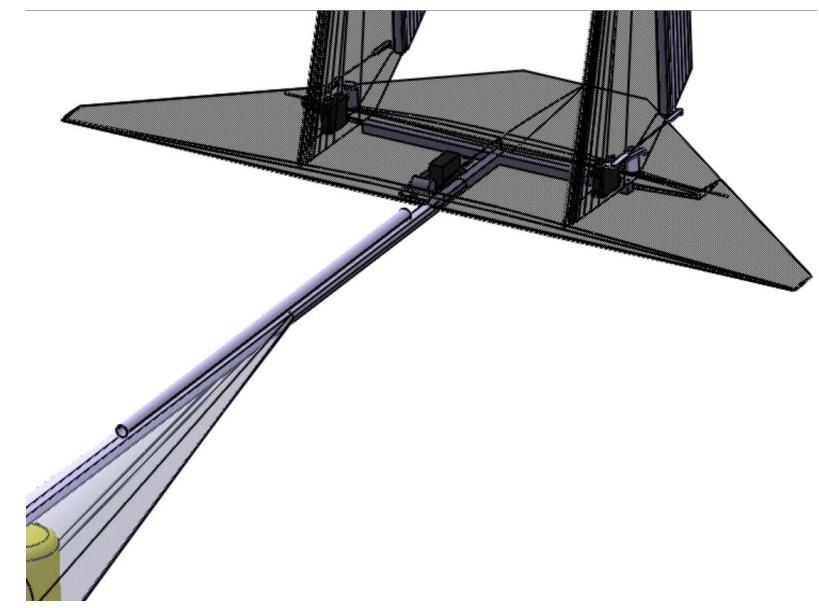

Figure 4. Tail boom structure.

\subsection{Wind Tunnel and Support}

The $6.5 \mathrm{~m} \times 5.5 \mathrm{~m}$ Low-Speed Wind Tunnel of JAXA was used. Figure 5 shows appearance of the test section. The type of the wind tunnel is a closed-circuit and continuous-atmospheric type. The size of the test section is $6.5 \mathrm{~m}$ high, $5.5 \mathrm{~m}$ wide, and octagonal with corner. The maximum and minimum wind speeds are 70 and $1 \mathrm{~m} / \mathrm{s}$, respectively. The airplane was supported using a strut, as shown in Figure 6. The airplane and the strut were connected using a rotational joint at the airplane's center of gravity. Therefore the airplane can rotate in a pitch direction.

\subsection{Video Grammetry System}

A position of each part of the airplane was measured using a motion capture system of VICON [11]. Figure 7 shows a principle of the video grammetry. This system uses multiple cameras. Markers are mounted on the test model. An angle between the camera axis and the line from the camera to the marker can be calculated from the obtained image. A position of a marker is determined using the information of the angles, the camera positions, and the camera directions. The positions and directions of the cameras are determined beforehand through calibration. In the calibration, a calibration wand that has markers at known position is shot by cameras at entire test space. An accuracy of the video grammetry depends on camera specifications (resolution, distortion, etc.), and relative position and attitude among cameras and markers.

In this test, four infrared cameras were used, as shown in Figure 8. The image data was processed by a software NEXUS. Two types of the marker were used: a ball type (see Figure 9) and a sticker type. The diameters of the ball and the sticker were both $14 \mathrm{~mm}$. The markers were made by retroreflective material. The ball type is good for marker detection because the shape of the marker in the image is always a circle; however, the ball type may change the flow around the test model. In contrast, for the sticker type, the detection is relatively difficult but the effect on the flow is small. This time we first tried to use the sticker type for 


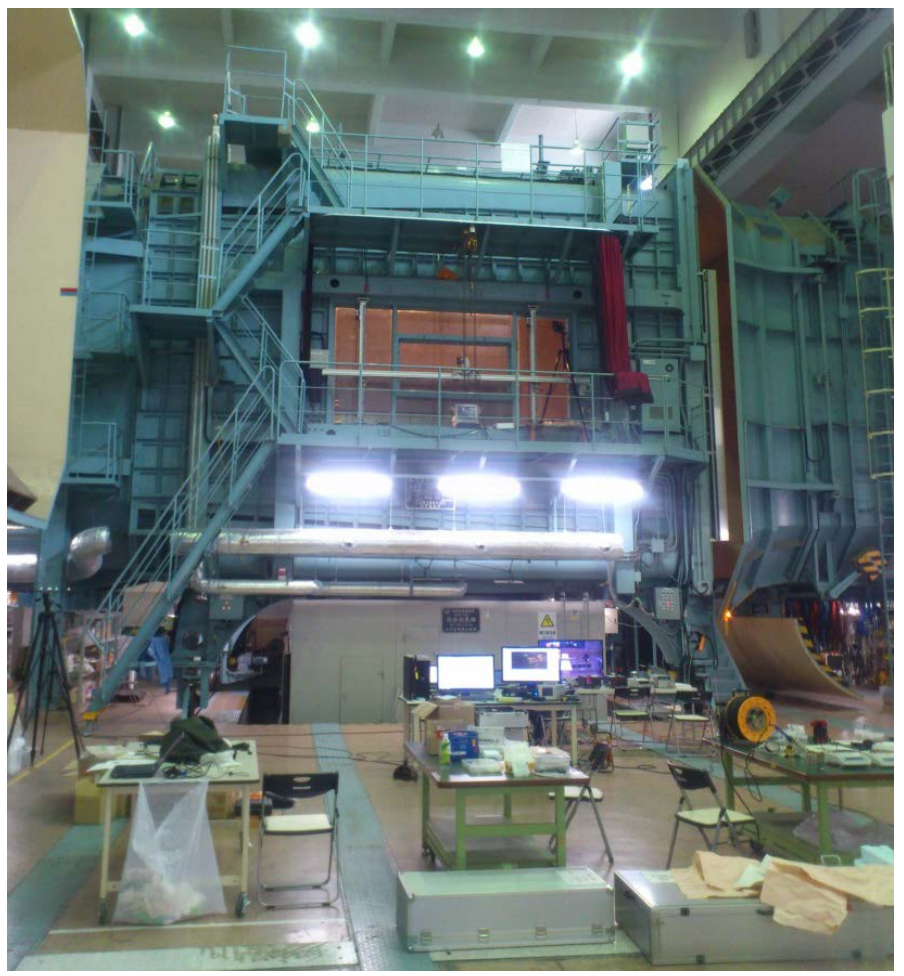

Figure 5. Appearance of test section.

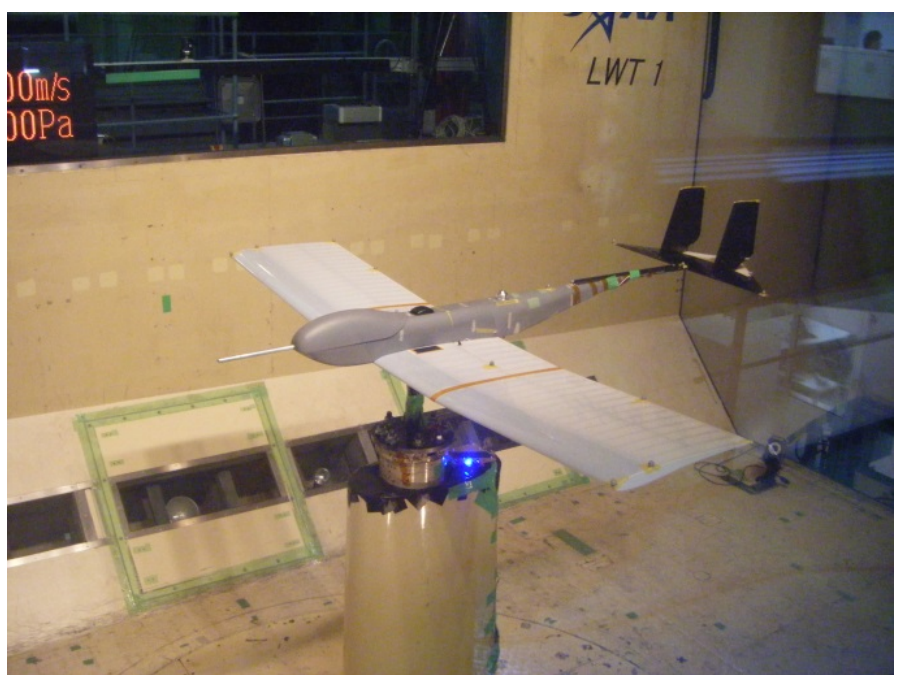

Figure 6. Set-up of airplane.

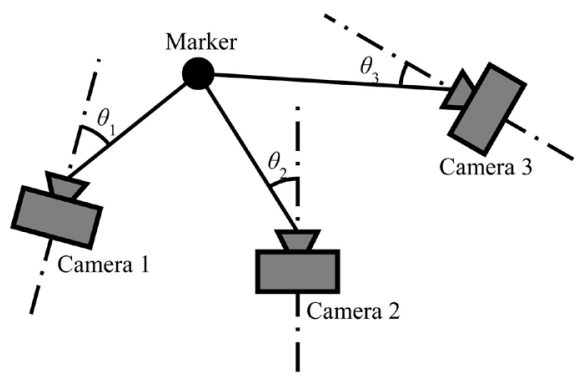

Figure 7. Principle of video grammetry. 


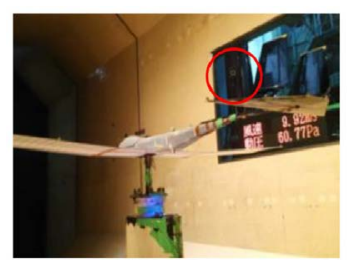

Upper, Right, Upstream

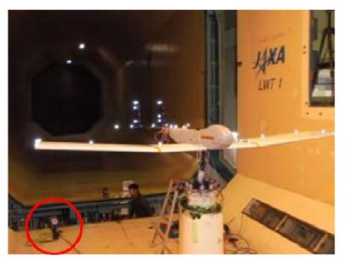

Lower, Right, Downstream

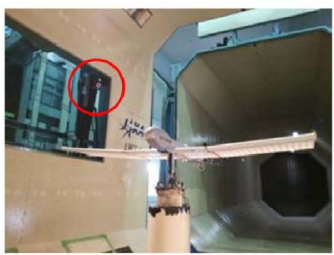

Upper, Right, Downstream

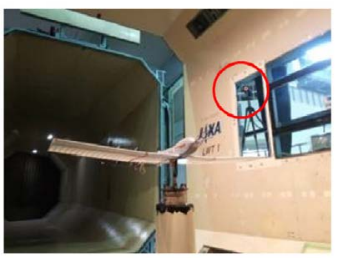

Upper, Left, Downstream

Figure 8. Location of cameras.

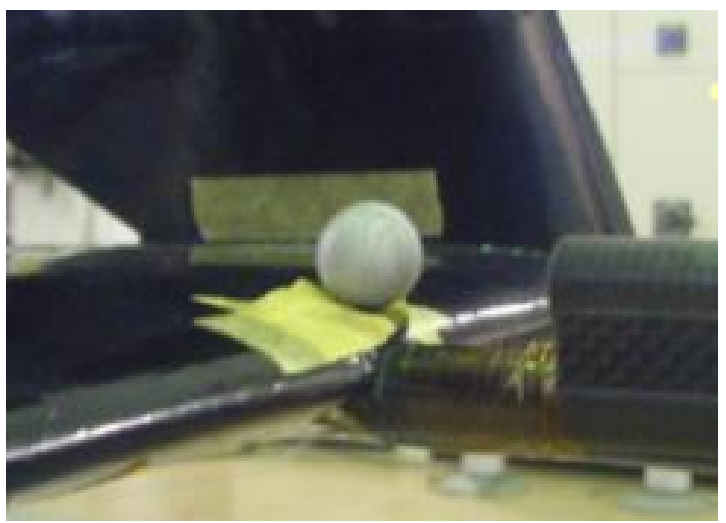

Figure 9. Ball type marker.

all position. Then some markers where the detection result was bad were changed to the ball type. Figure 10 shows the location of the markers. The markers were put on the various location of the airplane. As shown in Figure 11, five segments were defined using the markers: a fuselage, a right wing tip, a left wing tip, a tail, and an elevator. Each segment was treated as a rigid body and their position and attitude were calculated. Note that the position of the markers of the segment should be asymmetry to specify the attitude of the segment uniquely. Here, the upper surface of the elevator was covered by a white paper to prevent a misdetection of the reflection light of room lamps. In this test configuration, a standard deviation of a measured position of a stationary marker was $0.09 \mathrm{~mm}$.

\subsection{Experimental Conditions}

The targets of the deformation measurement were the followings:

- Main wing bending

- Main wing twisting

- Tail boom bending

- Elevator deflection angle change 

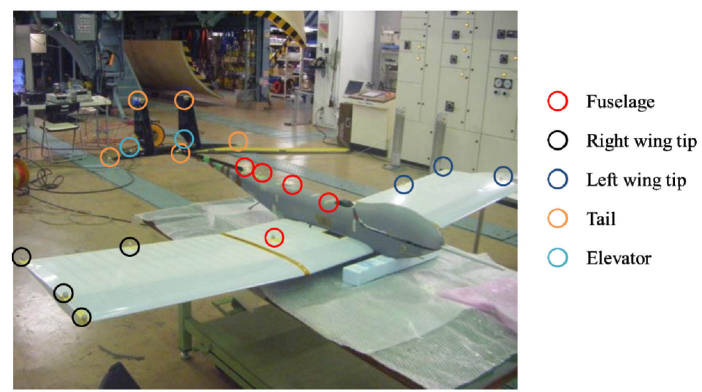

(a)
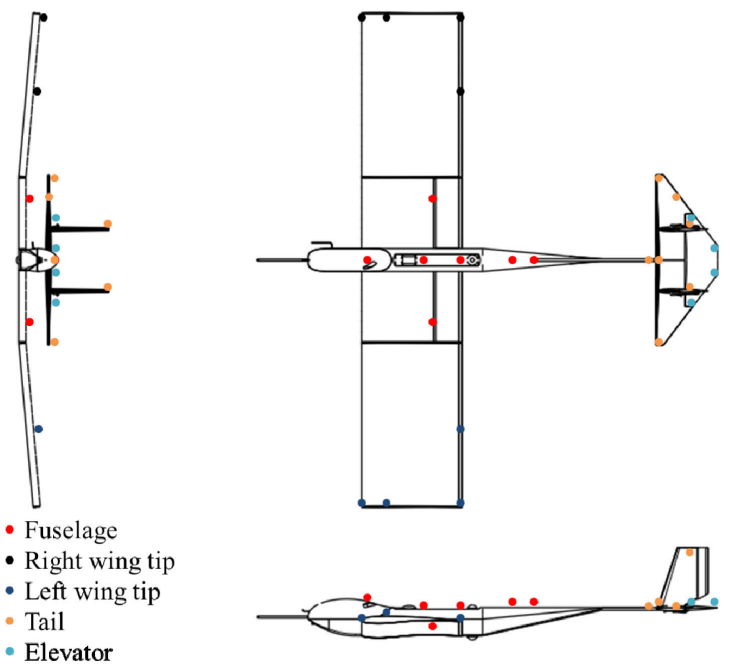

(b)

Figure 10. Location of markers. (a) Photo; (b) Three-view drawing.

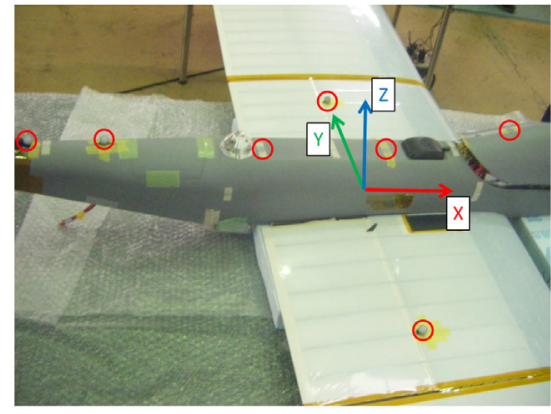

(a)

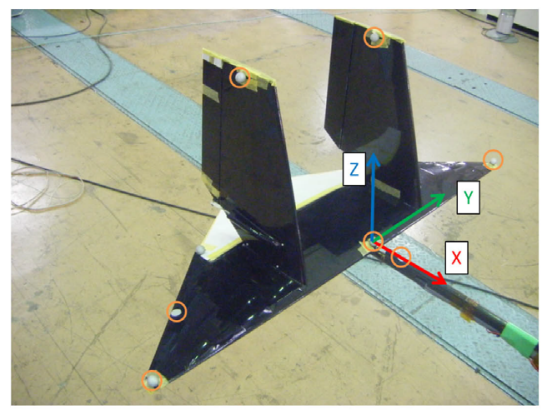

(c)

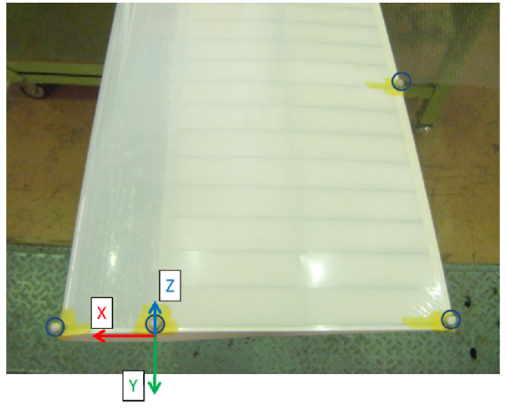

(b)

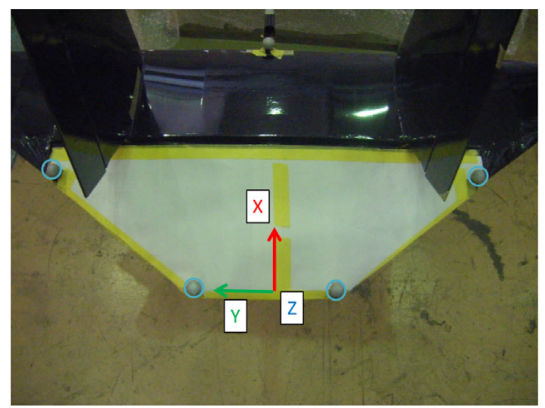

(d)

Figure 11. Segments. (a) Fuselage; (b) Wing tip (left); (c) Tail; (d) Elevator. 
These are shown in Figure 12. All parameters were measured as a change from a wind-off condition to a wind-on condition. The main wing bending was measured as the change of the position of the wing tip segments in body $Z$-coordinate. The main wing twisting was defined as a change of the relative pitch angle of the wing tip segments to the fuselage segment. The tail boom bending was defined as a change of the relative pitch angle of the tail segment to the fuselage segment. The elevator deflection angle was defined as a difference between pitch angles of the tail segment and the elevator segment.

One of the representative dynamic pressures for the flight test was $65 \mathrm{~Pa}$. To set the dynamic pressure to the flight test value, the velocity of flow was fixed to $10 \mathrm{~m} / \mathrm{s}$. Here, the Reynolds number based on the main wing chord length was $3.6 \times 10^{5}$. The aerodynamic force was changed by an angle of attack (AoA).

For the measurement of the main wing deformation, the rotational joint was unlocked and the AoA was changed by the elevator deflection. The elevator deflection angles were set to every 2.5 degrees from -2.5 degrees to 10.0 degrees. For the measurement of the tail boom and the elevator, the rotational joint was locked to 6 or 9 degrees. The elevator deflection angle was set from -20 degrees to 16 degrees.

\section{Results and Discussion}

The aerodynamic deformations of the main wing bending, the main wing twisting, the tail boom bending, and the elevator deflection angle change of the airplane for Mars exploration were measured in the wind tunnel using the video grammetry system. Each result and discussion is described in the following subsections. The error bars in figures show a standard deviation of each measurement result. This deviation includes effects of an accuracy of the video grammetry system and small oscillations of the UAV due to flow.

\subsection{Main Wing Bending}

Figure 13 shows the height change of the right and left wing tips from no-wind condition at each AoA to evaluate the main wing bending. The height change increased almost linearly with AoA. The measured maximum change was 5.6 $\mathrm{mm}$. The dihedral angle change by the bending $\Delta \Gamma$ can be calculated by the following equation:

$$
\Delta \Gamma=\tan ^{-1}(2 \Delta z / b)
$$

where, $\Delta z$ is the height changes of wing tip, and $b$ is the span $(=2.4[\mathrm{~m}])$. As a result, the estimated dihedral angle change by this bending was 0.3 degrees. The

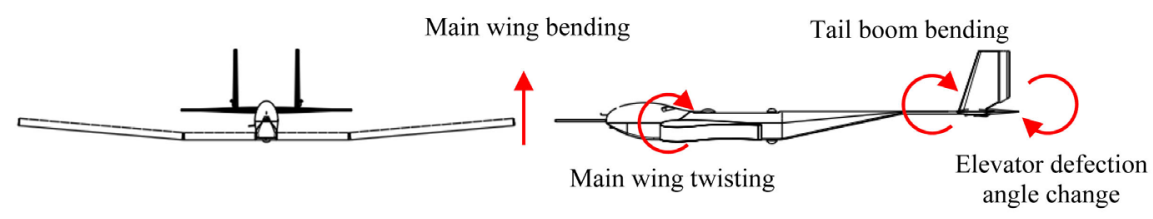

Figure 12. Measurement targets. 


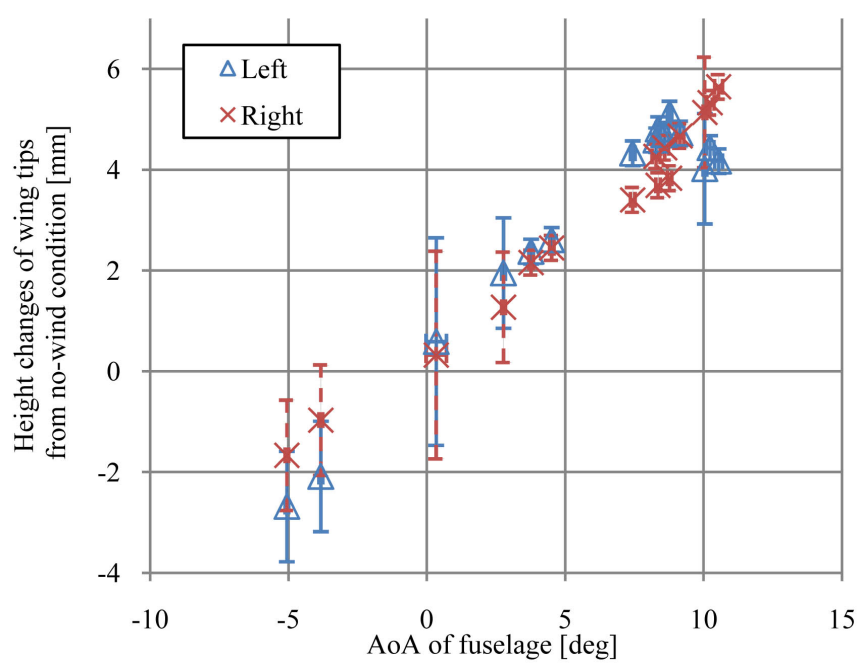

Figure 13. AoA vs. height changes of wing tips from no-wind condition.

dihedral angle affects to the derivative of rolling moment with respect to sideslip angle. The change of the derivative of a rectangular wing can be estimated using the wing element theory as follows:

$$
\Delta C_{l_{\beta}}=-a_{0} \Delta \Gamma / 4
$$

where $a_{0}$ is a lift slope. The lift slope of this airfoil was 0.07 [1/deg] in a previous wind tunnel test. For example, when the sideslip angle is 5 degrees, the change of the rolling moment coefficient is 0.0004 . This airplane can change the rolling moment coefficient from -0.016 to 0.016 using the ailerons. Therefore the measured change of the dihedral angle was sufficiently small. This result suggests that the main spar that was designed as a safety factor of 2.8 had enough strength for bending and the design method was valid for the lightweight airplane such as a Mars airplane.

\subsection{Main Wing Twisting}

Figure 14 shows a relation between AoA and twist angle changes of the right and left wing tips. When the angle of attack is near zero, the change of the twist angles of the wing tips from no-wind condition were about -0.3 degrees. The difference of the wing tip angles between right and left was about 0.1 degrees. The change rapidly increased when the angle of attack exceeded around 10 degrees. These tendencies can be understood from pitching moment characteristics of the main wing airfoil. The green triangle marker shows the pitching moment coefficient of the main wing airfoil [12]. The negative pitching moment twisted the main wing to leading-edge-down direction. The pitching moment rapidly decreases when the angle of attack exceeds 10 degrees. It is coincident to the tendency of the twist angles. Generally, the main wing twisting may show an effect of the low Reynolds number flow. For example, the pitching moment coefficient of a NACA0012 airfoil is not smooth due to the effect of the laminar separation bubble. However, such special tendency due to low Reynolds number flow 


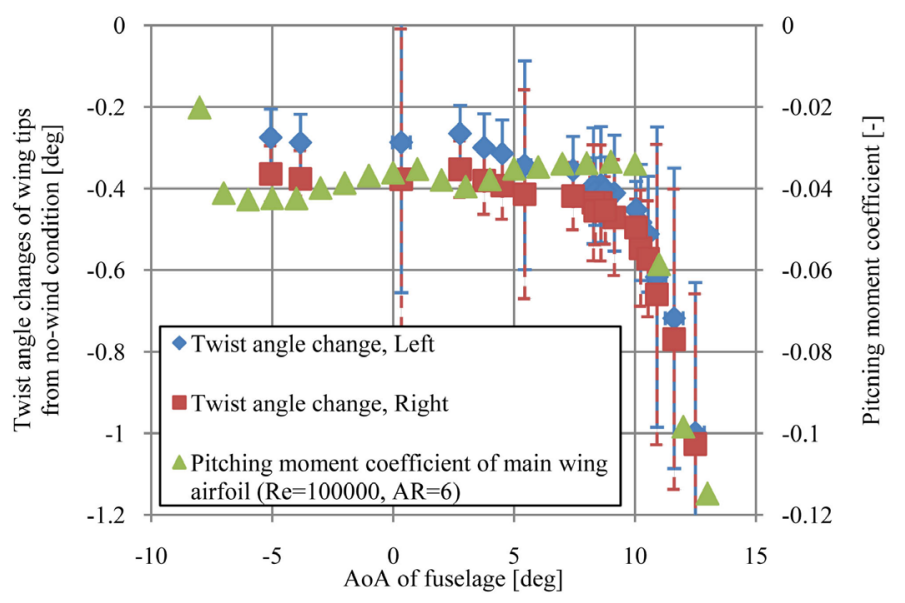

Figure 14. AoA vs. change of twist angle of main wing tips.

was not observed in this test because the aerodynamic performance of the Ishii airfoil is stable in low Reynolds number flow. That is one of the reasons why the Ishii airfoil is selected for the Mars airplane.

A symmetric twist of a wing causes a change of a lift. When the twist angle linearly change from 0 at the wing root to $\alpha_{t}$ at the wing tips, the change of the lift coefficient of the rectangular wing can be estimated using the wing element theory as follows:

$$
\Delta C_{L}=a_{0} \alpha_{t} / 2
$$

Therefore, when the changes of the twist angles of the wing tips are about -0.3 degrees, the change of the lift coefficient is -0.01 . This effect is sufficiently small.

An asymmetric twist of a wing causes a change of a rolling moment. When the twist angle linearly changes from $\alpha_{t}$ at the left wing tip to $-\alpha_{t}$ at the right wing tip, the change of the rolling moment coefficient of the rectangular wing can be estimated using the wing element theory as follows:

$$
\Delta C_{l}=a_{0} \alpha_{t} / 6
$$

Therefore, when the difference of the wing tip angle between right and left is 0.1 degrees, the change of the rolling moment coefficient is -0.0006 . As mentioned in section 3.1, this airplane can change the rolling moment coefficient from -0.016 to 0.016 using the ailerons. Therefore, this effect is sufficiently small.

As a conclusion, the result suggests that the main spar located on the center of pressure has enough strength for twisting. Note that, however, a large moment may act on the main spar at off-nominal condition such as high angle of attack and different Reynolds number. The designers of lightweight airplanes should consider not only the nominal condition but also off-nominal condition even though the main spar is located on the center of pressure at nominal condition.

\subsection{Tail Boom Bending}

Figure 15 shows a relation among the AoA, the elevator deflection angle, and the tail boom bending angle. The tail boom bending angle was measured as a 


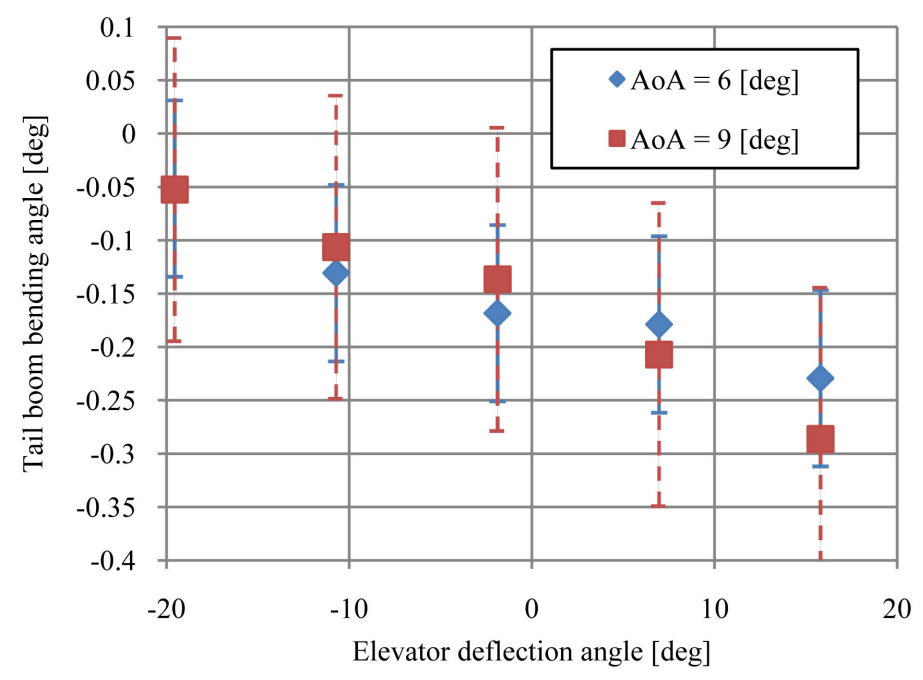

Figure 15. Elevator deflection angle vs. tail boom bending angle

change of a pitch angle of the tail segment from no-wind condition. The measured maximum tail boom bending angle was 0.3 degrees. The tail boom bending angle linearly decreased as the elevator deflection angle increased. The tail boom deformation due to the 36 degrees change of the elevator deflection was around 0.2 degrees. On the other hand, the deformation due to the 3 degrees change of the angle of attack was around 0.04 degrees. It suggests that the effect of the elevator deflection angle is larger than the effect of the angle of attack. This tendency seems to be appeared because the change of the lift force on the horizontal tail by the elevator deflection angle change is larger than that by the angle of attack change.

A tail boom bending affects to a pitching moment of an airplane. The change of the pitching moment coefficient due to the change of the angle of attack of the tail by bending can be estimated using the following equation:

$$
\Delta C_{M}=-a_{0} S_{H} l \Delta \alpha /(S c)
$$

where $\Delta \alpha$ is the tail boom bending angle. A horizontal tail area $S_{H}$ was $0.15 \mathrm{~m}^{2}$. A main wing area $S$ was $1.2 \mathrm{~m}^{2}$. A distance between the horizontal tail and the center of gravity $l$ was $1.4 \mathrm{~m}$. A chord length of the wing $c$ was $0.5 \mathrm{~m}$. In this condition, when the change of the angle of attack of the tail by bending is 0.3 degrees, the change of the pitching moment coefficient is 0.0072 . An adjustable range of the pitching moment coefficient using the elevator is around 0.1 for this airplane. Therefore the effect of the tail boom bending to the pitching moment coefficient is acceptable and the effect of the reinforcement by additional pipe on tail boom structure was sufficient.

\subsection{Elevator Deflection Angle Change}

Figure 16 shows a relation among the AoA, the elevator deflection angle command, and the change of the elevator deflection angle from the command. A data acquisition at AoA of 16 degrees was failed due to a segment recognition error 


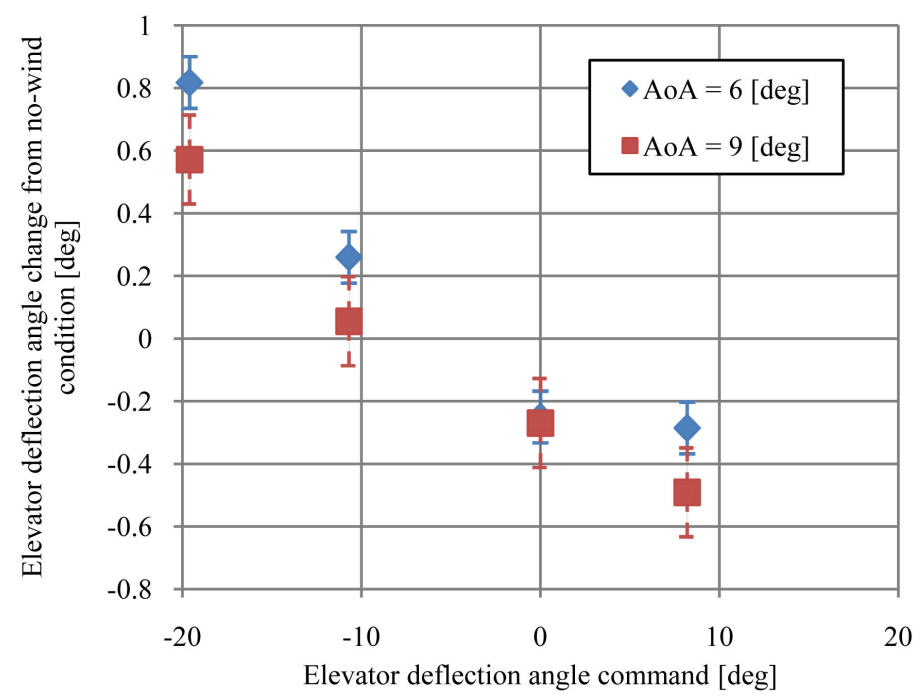

Figure 16. Elevator deflection angle command vs. change from no-wind condition.

in the video grammetry. The tendency of the figure shows that the elevator was deformed to main stream direction. Even though the servo was located near the elevator, the maximum change of 0.8 degrees was measured at the command of -20 degrees. It was $4 \%$ of the command. This information can be used for a correction of the elevator control, an evaluation of the flight test result, and design of other lightweight airplanes.

\section{Conclusion}

The aerodynamic deformations of the MABE-1 (actual UAV) were measured in the wind tunnel using the video grammetry technique. The measured deformations were the main wing bending, the main wing twisting, the tail boom bending, and the elevator deflection angle change. The main wing bending was linearly changed with AoA. The amount of the bending deformation was sufficiently small; therefore the main spar had enough strength by designing as the safety factor of 2.8 at the load factor of 5 . The main wing twisting was rapidly increased when the AoA exceeded 10 degrees. To locate the main spar on the center of pressure was effective; however designer should consider not only a nominal condition but also off-nominal condition. The elevator deflection angle had a non-negligible effect to the tail boom bending even if the AoA was fixed. Even though the servo motor was located near the elevator to shorten the linkage, the maximum difference between command and actual elevator deflection angle in flow was $4 \%$. These deformations were obtained at the representative dynamic pressure at horizontal flight phase, $65 \mathrm{~Pa}$. Note that a larger deformation is expected at higher dynamic pressure environment such as pull-up phase. The airplane should be operated considering the effects of these deformations.

\section{Acknowledgements}

This work was partially supported by a Grant-in-Aid for Scientific Research (A), 
and it was carried out as part of collaborative research on a specific subject by ISAS/JAXA.

\section{Conflicts of Interest}

The authors declare no conflicts of interest regarding the publication of this paper.

\section{References}

[1] Nagai, H., Oyama, A. and Mars Airplane, W.G. (2013) Mission Scenario of Mars Exploration by Airplane. Proceedings of the 2013 Asia-Pacific International Symposium on Aerospace Technology, Takamatsu, November 2013, 08-01-3 p.

[2] Nagai, H., Anyoji, M., Nonomura, T., Oyama, A., Okamoto, M., et al. (2015) Aerodynamic Challenge to Realize Mars Airplane. Proceedings of the 30 th International Symposium on Space Technology and Science, Kobe, July 2015.

[3] Nagai, H., Oyama, A. and Mars Airplane, W.G. (2015) Development of Mars Exploration Aerial Vehicle in Japan. Proceedings of the 30 th International Symposium on Space Technology and Science, Kobe, July 2015.

[4] Nagai, H. and Oyama, A. (2016) Development of Japanese Mars Airplane. Proceedings of the 67 th International Astronautical Congress, Guadalajara, September 2016, IAC-16-A3.3A.5x35104.

[5] Oyama, A., et al. (2017) Flight System of Mars Airplane Balloon Experiment-1 (MABE-1). Proceedings of the 31 st International Symposium on Space Technology and Science, Matsuyama, June 2017, 2017-k-42.

[6] Fujita, K., Tokutake, H., Nagai, H. and Oyama, A. (2017) Flight Control Parameter Design for Mars Airplane Balloon Experiment-1 (MABE-1) Using Evolutionary Computation. Proceedings of the 31 st International Symposium on Space Technology and Science, Matsuyama, June 2017, 2017-k-42.

[7] Anyoji, M., Okamoto, M., Fujita, K., Nagai, H. and Oyama, A. (2017) Evaluation of Aerodynamic Characteristics on Mars Airplane Balloon Experiment-1 (MABE-1). Proceedings of the 31 st International Symposium on Space Technology and Science, 2017-k-42, Matsuyama, June 2017.

[8] Barrows, D. (2007) Video Grammetric Model Deformation Measurement Technique for Wind Tunnel Applications. Proceedings of the 45th AIAA Aerospace Sciences Meeting and Exhibit, Reno, 10-13 January 2007.

https://doi.org/10.2514/6.2007-1163

[9] Black, J.T., Pitcher, N.A., Reeder, M.F. and Maple, R.C. (2010) Video Grammetry Dynamics Measurements of a Lightweight Flexible Wing in a Wind Tunnel. Journal of Aircraft, 47, 172-180. https://doi.org/10.2514/1.44545

[10] JR PROPO Deutschland, RC-BEREICH/SENDER/SERVOS/ELEKTRONIK, Servos, DS189HV High Voltage Wing Servo.

https://jr-propo.de/shop/ds189hv-high-voltage-wing-servo-p-185.html?language=en

[11] VICON, Software, Nexus (2017). https://www.vicon.com/products/software/nexus

[12] Shigeoka, S., Yonemoto, K., and Ochi, H. (2011) Variable-Pressure Wind Tunnel Study of Aspect Ratio Effects on Three-Dimensional Wing at Low Reynolds number Flow. Proceedings of the 64th Kyushu Branch Regular Meeting of the Japan Society of Mechanical Engineers, C42, Kyushu University, Fukuoka. 